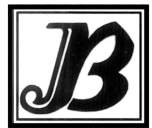

J. Bio-Sci. 29(2): 81-91, 2021 (December)

ISSN 1023-8654 http://www.banglajol.info/index.php/JBS/index

DOI: https://doi.org/10.3329/jbs.v29i2.54957

\title{
PREVALENCE AND ANTIBIOTIC RESISTANCE PATTERS OF ESCHERICHIA COLI ISOLATED FROM MILK AND MILK PRODUCT
}

\author{
T Sultana ${ }^{1}$, MF Rabbi ${ }^{1}$, BR Sarker ${ }^{1}$, MS Islam², MIA Begum ${ }^{1}$ and KMM Hossain ${ }^{1 *}$ \\ ${ }^{1}$ Department of Veterinary and Animal Sciences, University of Rajshahi, Rajshahi-6205, Bangladesh \\ ${ }^{2}$ Department of Surgery, Rajshahi Medical College, Rajshahi-6000, Bangladesh
}

\begin{abstract}
Milk contains many nutrients including carbohydrate, protein, fat, vitamins and minerals. Milk protein has high nutritional value because it contains all the essential amino acids. Considering the nutritive value, milk is widely consumed by the people as an ideal food. The biochemical changes in milk and milk products by microorganisms can be either desirable or undesirable. The safety of milk and milk products with respect to food borne diseases is of great concern around the world. Therefore, the present study was undertaken to determine the prevalence of Escherichia coli in milk and milk product with their antibiogram assay. A total of 150 milk and milk product (yogurt) samples were collected from Rajshahi Metropolitan area of Bangladesh and analyzed by cultural, staining and biochemical tests for the isolation and identification of $E$. coli. Antibiogram assay of all the isolates were done by disk diffusion method. The overall prevalence of E. coli was $20.0 \%$ in milk and milk product (yogurt) in Rajshahi Metropolitan area. The prevalence of $E$. coli was $26.0 \%$ and $34.0 \%$ in raw milk and in milk product (yogurt), respectively. E. coli was not detected in pasteurized milk in this study. In antibiogram assay, isolated E. coli showed $100.0 \%, 60.0 \%, 40.0 \%, 40.0 \%, 33.3 \%, 33.3 \%, 20.0 \%$, and $10.0 \%$ resistance to penicillin, gentamycin, ampicillin, streptomycin, amoxycillin, sulfamethoxasole-trimethoprim, nalidixic acid, and ciprofloxacin, respectively. The isolates also showed $73.3 \%, 60.0 \%, 53.3 \%, 53.3 \%, 30.0 \%$, $23.3 \%$, and $20 \%$ sensitive to ciprofloxacin, nalidixic acid, sulfamethoxasole-trimethoprim, streptomycin, amoxycillin, ampicillin, and gentamycin, respectively. The findings of this experiment speculated that the use of ciprofloxacin and nalidixic acid may have the preference in the clinical control of milk borne $E$. coli infection in Bangladesh.
\end{abstract}

Key words: Antibiotic resistance, E. coli, Milk and milk product, Prevalence

\section{Introduction}

Milk is a fresh, clean and normal mammary secretion obtained by milking of one or more dairy animals for nourishment of their offspring (Rani and Maheshwari 2012). It is widely consumed food that is essential for the diet not only for human but also newborn animals because it provides important macro and micro nutrients such as vitamins and minerals. Milk products also contain many nutrients and provide a quick and easy way of supplying these nutrients to the diet within relatively few calories. It is highly recommended to consume milk and milk products as part of a healthy balanced diet. Consumption of milk and milk products has been associated with numerous health benefits. On the other hand, milk is an excellent medium for the growth of a large number of bacteria including Staphylococcus aureus, Salmonella sp., E. coli, and Listeria $\mathrm{sp}$. which are responsible for causing numerous foodborne illnesses. Bacterial contamination of milk usually

*Author for correspondence: mozaffor@ru.ac.bd 
occurs during the milking process and this depends on sanitary condition of the environment, utensils used for milking, and milking personnel. It could also result from microorganisms that enter the udder through the teat canal (Smith et al. 2007). The safety of milk with respect to food borne diseases is of great concern around the World. The $E$. coli is a multi-talented, enteric, Gram-negative, rod shaped, flagellated, motile, oxidase negative, and facultative anaerobic bacteria under the family Enterobacteriaceae. The strains of $E$. coli are widely distributed in nature, being present in soil and surface water, and in animal and human feces. The $E$. coli is found habitually in the large intestine of vertebrates usually as a part of the normal flora. The E. coli and other facultative anaerobes constitute about $0.1 \%$ of gut flora (Eckburg et al. 2009) and oro-fecal transmission is the major route through which pathogenic strains of the bacterium cause disease. Most strains of $E$. coli live as commensals, many perhaps all are opportunistic pathogens of humans and animals (Levine 1984). There are also pathogenic strains of $E$. coli that when ingested, cause gastrointestinal illness in healthy humans and animals. The pathogenicity of $E$. coli strains is due to the presence of one or more virulence factors including invasiveness factors, heat labile and heat stable enterotoxins, verotxins, and colonization factors (Smith and Haibs 1967). Two types of enterotoxins are produced by enterotoxigenic $E$. coli (ETEC); a high molecular weight, immunogenic, heat labile toxin (LT) and/or a low molecular weight, non-immunogenic, heat stable toxin (ST). The shiga toxigenic E. coli (STEC) strains have also been described in Latin America, India and other developing countries (Kaddu-Mulindw et al. 2001). In Bangladesh, the predominant group of $E$. coli associated with childhood diarrhea is enterotoxigenic $E$. coli accounting for approximately $20 \%$ of all diarrheal cases (Qadri et al. 2005). Antibiotic is randomly being used for the treatment purpose in Bangladesh for many years. Knowledge of antimicrobial sensitivity pattern is important in selecting the appropriate therapy. Most of the people are not well aware about the schedule of antibiotic course. As a result, a new generation of virulent and resistant type of $E$. coli is produced due to incomplete course of treatment of man and animal (Marshall et al. 1990). Therefore, new generation of antibiotics will be required for the prevention and control of such type of bacterial diseases. Additionally, $E$. coli is genetically the most versatile bacterium and is the source of many plasmid and phage mediated genes (Saylers and Whitt 2002). The present study was therefore conducted to isolate and identify $E$. coli from milk and milk product and antimicrobial sensitivity assay of this bacterium that has public health significance.

\section{Materials and Methods}

\section{The study area and sources of samples}

The study was conducted in raw milk, pasteurized milk, and milk product (yogurt) collected from different farms and sale outlets in Rajshahi Metropolitan area of Bangladesh. Fifty raw milk samples (10 from each farm), fifty pasteurized milk samples (10 from each company), and fifty milk product (yogurt) samples (10 from each selling shops) were randomly collected and brought to the Microbiology Laboratory, Department of Veterinary and Animal Sciences, University of Rajshahi, Rajshahi-6205, Bangladesh. Yogurt samples were diluted with distilled water for the isolation and identification of $E$. coli.

\section{Isolation and identification of $E$. coli}

After enrichment in nutrient broth, a loopful of enriched culture was taken on a sterile glass slide and Gram's staining was performed for morphology study. Then the broth culture of bacteria was inoculated on nutrient agar by streak plate technique and inoculated at $37^{\circ} \mathrm{C}$ for 24 hours for the development of colonies. The 
colony on primary culture was repeatedly sub-cultured on different selective culture media (EMB agar, MacConkey agar and blood agar) by the streak plate technique until the pure culture with homogenous colonies was obtained. Identification of $E$. coli was done through a series of biochemical tests.

\section{Colony morphology}

The colony morphology of the isolated E. coli was studied as mentioned by Merchant and Packer (1967). Colony morphology such as shape, size, surface texture, edge and elevation, color, and opacity developed after 24 hours of incubation were carefully studied and recorded.

\section{Gram's staining}

Gram's staining was performed according to the method described by Cheesbrough (1985). In brief, a small colony was picked up with a bacteriological loop, smeared on separate glass slides and fixed by gently heating. Crystal violet was applied on each smear to stain for two minutes and washed with running tap water. Few drops of Gram's iodine was added as mordent for one minute and again washed with running tap water. Acetone alcohol was added for a few seconds as a decolouring agent. After washing with water, safranin was added as a counter stain and allowed to stain for 2 minutes. The slides were washed with water, blotted and dried in air, and examined under a microscope with high power objective (100X) using immersion oil.

\section{Biochemical studies for the identification of $E$. coli}

Pure culture of $E$. coli was subjected to different biochemical tests like sugar fermentation test (with five basic sugars for the production of acid with or without $\mathrm{H}_{2} \mathrm{~S}$ gas), catalase test, indole test, MR test, VP test, Simmon's citrate reaction and TSI agar slant reaction. Standard methods were followed to conduct these tests and interpretation (Cowan 1985).

\section{Antibiogram assay of isolated $E$. coli}

The disk diffusion method (Bauer et al. 1966, Jorgensen and Turnidge 2015) was used to test the antibiotic susceptibility of the $E$. coli isolates. In brief, pure colonies of the $E$. coli isolates were separately inoculated in nutrient broth and incubated at $37^{\circ} \mathrm{C}$ for overnight. Then $100 \mu \mathrm{l}$ of broth culture was taken and placed on Mueller Hinton agar plate and spread evenly with a sterile glass rod spreader. The antibiotic disks were placed on the surface of the agar plates keeping about $1 \mathrm{~cm}$ apart. After 18 to 20 hours of incubation at $37^{\circ} \mathrm{C}$, each agar plate was examined. The susceptibility test of the $E$. coli was done against eight commonly used antibiotic including; penicillin, gentamycin, ampicillin, amoxycillin, streptomycin, ciprofloxacin, sulfamethoxazole-trimethoprim, and nalidixic acid. According to the Clinical and Laboratory Standards Institute (CLSI 2017) susceptibility zones were measured and interpreted (Table 1). 
Table 1. Zone diameter interpretative standards for antimicrobial resistance

\begin{tabular}{lcccc}
\hline Name of used antibiotics & $\begin{array}{c}\text { Disk concentration } \\
(\mu \mathrm{g} / \text { disk })\end{array}$ & \multicolumn{3}{c}{$\begin{array}{c}\text { Interpretation of results } \\
\text { (zone diameter in mm) }\end{array}$} \\
\cline { 3 - 5 } & & $\mathrm{R}$ & $\mathrm{I}$ & $\mathrm{S}$ \\
\hline Penicillin & 10 & $\leq 11$ & $12-21$ & $\geq 22$ \\
Gentamycin & 10 & $\leq 12$ & $13-14$ & $\geq 15$ \\
Ampicillin & 25 & $\leq 13$ & $14-16$ & $\geq 17$ \\
Amoxycillin & 30 & $\leq 13$ & $14-17$ & $\geq 18$ \\
Streptomycin & 10 & $\leq 11$ & $12-14$ & $\geq 15$ \\
Ciprofloxacin & 5 & $\leq 15$ & $16-20$ & $\geq 21$ \\
Sulfamethoxazole-trimethoprim & 25 & $\leq 10$ & $11-15$ & $\geq 16$ \\
Nalidixic acid & 30 & $\leq 14$ & $15-16$ & $\geq 17$ \\
\hline
\end{tabular}

Results

\section{Cultural characteristics}

The growth of $E$. coli on nutrient agar was indicated by the development of smooth, circular, white to grayish white colonies and on EMB by the development of smooth, circular, greenish-black color colonies with metallic sheen (Fig. 1). The growth of $E$. coli on MacConkey agar was indicated by the development of bright pink colored colonies and on blood agar by the development of colorless colonies without hemolysis (Table 2).

\section{Staining characteristics}

The staining characteristics of the isolated $E$. coli were determined by Gram's staining technique. The microscopic examination of Gram's stained smears of $E$. coli revealed Gram's negative, small rod shaped appearance, arranged in single or paired (Fig. 2 and Table 2).

Table 2. Morphology and cultural characteristics of isolated $E$. coli on different agar media

\begin{tabular}{|c|c|c|c|c|}
\hline \multicolumn{4}{|c|}{ Cultural characteristics of $E$. coli on different agar media } & \multirow{2}{*}{$\begin{array}{l}\text { Staining } \\
\text { characteristics }\end{array}$} \\
\hline Nutrient agar & MacConkey agar & EMB agar & Blood agar & \\
\hline $\begin{array}{l}\text { Circular, clear, } \\
\text { moist, smooth, } \\
\text { low convex and } \\
\text { glistening } \\
\text { colonies. }\end{array}$ & $\begin{array}{l}\text { Bright pink colored, } \\
\text { transparent, smooth, } \\
\text { raised colonies. }\end{array}$ & $\begin{array}{l}\text { Greenish- black } \\
\text { color colonies } \\
\text { with metallic } \\
\text { sheen. }\end{array}$ & $\begin{array}{l}\text { Colorless } \\
\text { colonies without } \\
\text { hemolysis. }\end{array}$ & $\begin{array}{l}\text { Gram negative, } \\
\text { small rod shaped } \\
\text { appearance, } \\
\text { arranged in single } \\
\text { or paired. }\end{array}$ \\
\hline
\end{tabular}




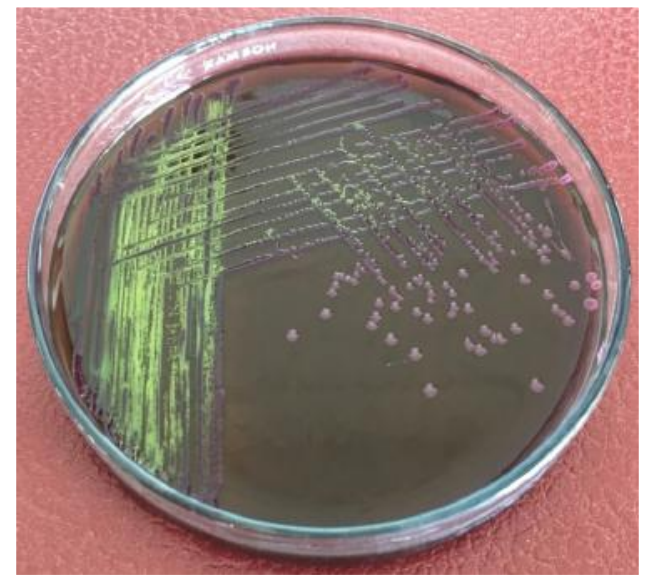

Fig. 1: Growth of $E$. coli on EMB agar (greenish-black color colonies with metallic sheen).

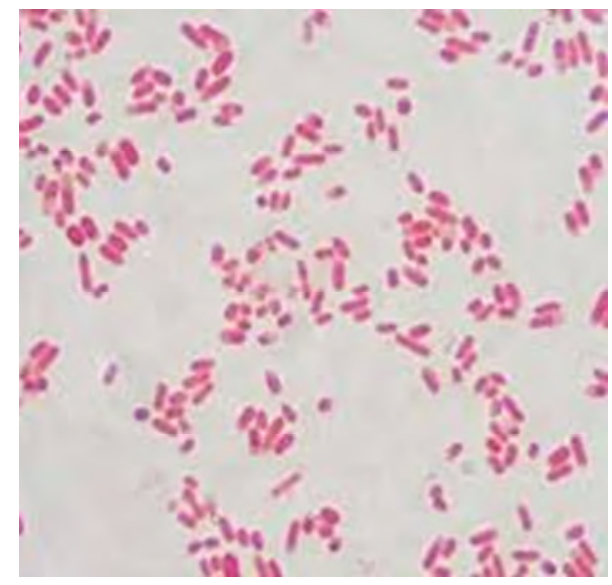

Fig. 2: Gram's stained E. coli (Gram's negative, pink colored, small rod shaped appearance, arranged in single or paired under a light microscope).

\section{Biochemical properties}

Isolated E. coli fermented dextrose, lactose, sucrose, maltose, and mannitol with the production of acid and gas in sugar fermentation test (Fig. 3). Isolated E. coli showed positive results in catalase test, indole test and MR test but showed negative result in VP test and Simmon's citrate reaction (Table 3). Isolated E. coli produced acidic slant and acidic butt (yellow slant and yellow butt) with gas production in TSI agar slant reaction (Table 3).

Table 3. Biochemical properties of isolated E. coli

\begin{tabular}{|c|c|c|c|c|}
\hline Tests & Used sugars & Acid production & Gas production & Results \\
\hline \multirow{5}{*}{$\begin{array}{l}\text { Fermentation reaction with five } \\
\text { basic sugars }\end{array}$} & Dextrose & + & + & + \\
\hline & Maltose & + & + & + \\
\hline & Lactose & + & + & + \\
\hline & Sucrose & + & + & + \\
\hline & Mannitol & + & + & + \\
\hline \multicolumn{4}{|l|}{ Indole test } & + \\
\hline \multicolumn{4}{|l|}{ Catalase test } & + \\
\hline \multicolumn{4}{|l|}{ MR test } & + \\
\hline \multicolumn{4}{|l|}{ VP test } & - \\
\hline \multicolumn{4}{|l|}{ Simmon's citrate reaction } & - \\
\hline TSI agar slant reaction & \multicolumn{3}{|c|}{$\begin{array}{l}\text { Acidic slant and acidic butt (yellow slant and yellow butt) } \\
\text { with gas production }\end{array}$} & + \\
\hline
\end{tabular}




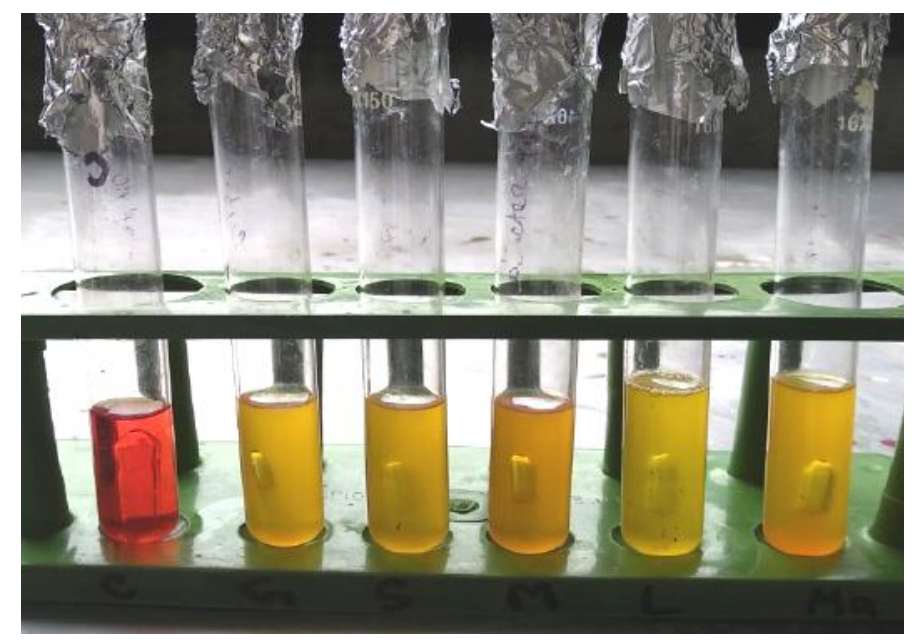

Fig. 3: Fermentation activity of isolated E. coli with five basic sugars (fermented dextrose, lactose, sucrose, maltose, and mannitol with the production of acid and gas).

\section{Prevalence of $E$. coli in milk and milk product in Rajshahi Metropolitan area}

The overall prevalence E. coli in milk and milk product (yogurt) was $20.0 \%$ in Rajshahi Metropolitan area of Bangladesh (Table 3). The prevalence E. coli was $26.0 \%$ in raw milk (Table 4) and $34.0 \%$ in milk product (Table 5). The prevalence E. coli was zero percent in pasteurized milk in Rajshahi Metropolitan area.

Table 3. Overall prevalence of $E$. coli in milk and milk product in Rajshahi Metropolitan area

\begin{tabular}{lccccc}
\hline Name of samples & $\begin{array}{c}\text { No. of } \\
\text { samples } \\
\text { tested }\end{array}$ & $\begin{array}{c}\text { No. of } \\
\text { positive } \\
\text { samples }\end{array}$ & $\begin{array}{c}\text { Percentage of } \\
\text { positive } \\
\text { samples }\end{array}$ & $\begin{array}{c}\text { Total } \\
\text { positive } \\
\text { samples }\end{array}$ & $\begin{array}{c}\text { Overall } \\
\text { prevalence } \\
(\%)\end{array}$ \\
\hline Raw milk & 50 & 13 & $26.0 \%$ & & \\
Milk product (yogurt) & 50 & 17 & $34.0 \%$ & 30 & $20.0 \%$ \\
Pasteurized milk & 50 & 0 & 0 & & \\
\hline
\end{tabular}

Table 4. Prevalence of $E$. coli in raw milk in Rajshahi Metropolitan area

\begin{tabular}{lccc}
\hline Name of samples & No. of samples tested & No. of positive samples & Overall prevalence (\%) \\
\hline RM 1 & 10 & 3 & \\
RM 2 & 10 & 2 & $26.0 \%$ \\
RM 3 & 10 & 3 & \\
RM 4 & 10 & 3 & \\
RM 5 & 10 & 2 & \\
\hline
\end{tabular}

RM = Raw milk. 
Table 5. Prevalence of $E$. coli in milk product in Rajshahi Metropolitan area

\begin{tabular}{lccc}
\hline Name of samples & No. of samples tested & No. of positive samples & Overall prevalence (\%) \\
\hline MP 1 & 10 & 4 & \\
MP 2 & 10 & 2 & $34.0 \%$ \\
MP 3 & 10 & 3 & \\
MP 4 & 10 & 4 \\
MP 5 & 10 & 4 \\
\hline
\end{tabular}

$\mathrm{MP}=$ Milk product.

\section{Antibiotic sensitivity and resistance patterns of the isolated E. coli}

The results of antibiotic sensitivity assay of isolated $E$. coli showed $100.0 \%, 60.0 \%, 40.0 \%, 40.0 \%, 33.3 \%$, $33.3 \%, 20.0 \%$, and $10.0 \%$ resistance to penicillin, gentamycin, ampicillin, streptomycin, amoxycillin, sulfamethoxasole-trimethoprim, nalidixic acid, and ciprofloxacin, respectively (Table 6 and Fig. 5). In sensitivity assay, isolates showed $73.3 \%, 60.0 \%, 53.3 \%, 53.3 \%, 30.0 \%, 23.3 \%$, and $20 \%$ sensitive to ciprofloxacin, nalidixic acid, streptomycin, sulfamethoxasole-trimethoprim, amoxycillin, ampicillin, and gentamycin, respectively ( Table 6 and Fig. 5). There was no sensitivity found to penicillin (Table 6 and Fig. 4). The isolates also showed intermediate sensitive to ampicillin (36.7\%), amoxycillin (36.7\%), gentamycin (20.0\%), nalixic acid (20.0\%), ciprofloxacin (16.7\%), sulfamethoxasole-trimethoprim (13.3\%), and streptomycin (6.7\%).

Table 6. Antibiotic sensitivity and resistance patterns of isolated E. coli

\begin{tabular}{lccc}
\hline Name of used antibiotics & \multicolumn{3}{c}{ Resistance patterns $(\mathrm{n}=30)$} \\
\cline { 2 - 4 } & Sensitive (\%) & Intermediate sensitive (\%) & Resistant (\%) \\
\hline Penicillin & 0 & 0 & $30(100 \%)$ \\
Gentamycin & $6(20.0 \%)$ & $6(20.0 \%)$ & $18(60.0 \%)$ \\
Ampicillin & $7(23.3 \%)$ & $11(36.7 \%)$ & $12(40.0 \%)$ \\
Amoxycillin & $9(30.0 \%)$ & $11(36.7 \%)$ & $10(33.3 \%)$ \\
Streptomycin & $16(53.3 \%)$ & $2(6.7 \%)$ & $12(40.0 \%)$ \\
Ciprofloxacin & $22(73.3 \%)$ & $5(16.7 \%)$ & $3(10.0 \%)$ \\
Sulfamethoxazole-trimethoprim & $16(53.3 \%)$ & $4(13.3 \%)$ & $10(33.3 \%)$ \\
Nalidixic acid & $18(60.0 \%)$ & $6(20.0 \%)$ & $6(20.0 \%)$ \\
\hline
\end{tabular}




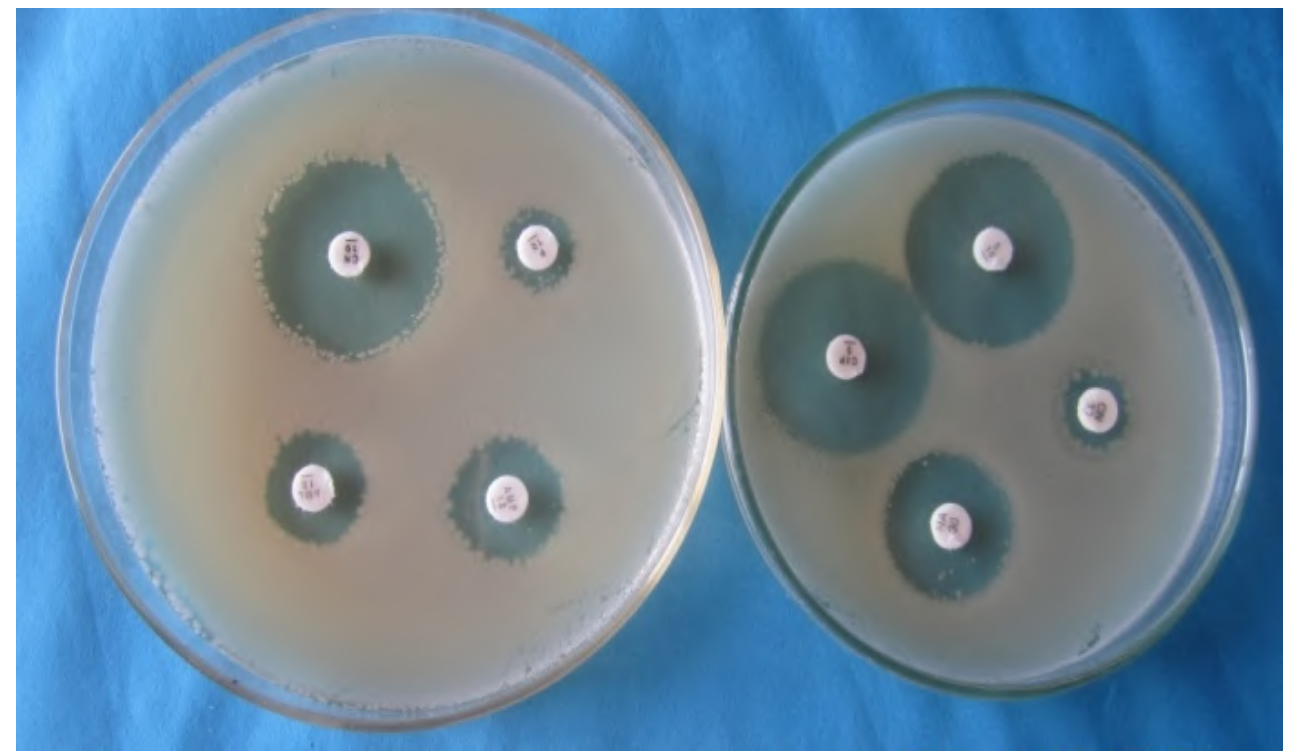

Fig. 4: Antibiotic sensitivity and resistance patterns of isolated $E$. coli on Mueller Hinton agar.

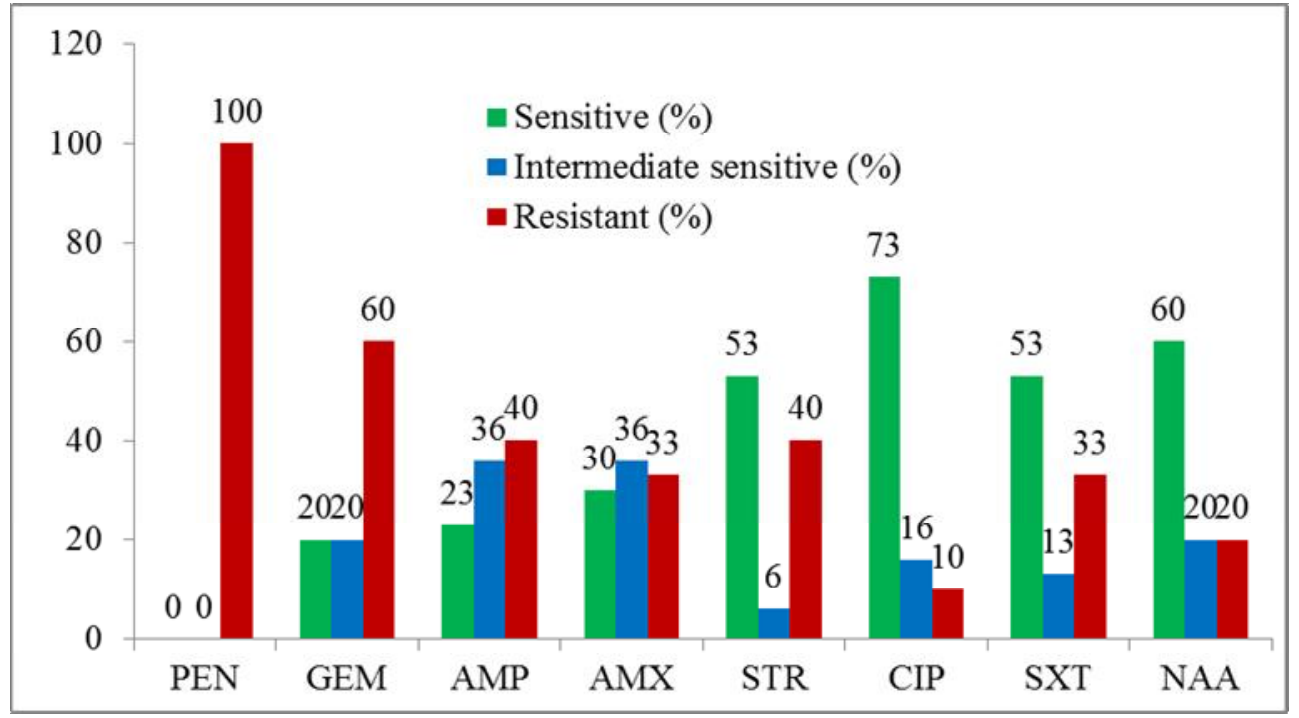

Fig. 5: Antibiotic sensitivity and resistance patterns of isolated $E$. coli (PEN = Penicillin, GEN = Gentamycin, AMP = Ampicillin, AMX = Amoxycillin, STR = Streptomycin, CIP = Ciprofloxacin, SXT = Sulfamethoxazole-trimethoprim, and NAA = Nalidixic acid). 


\section{Discussion}

In the present study the overall prevalence of $E$. coli was $20.0 \%$ in milk and milk product (yogurt) in Rajshahi Metropolitan area of Bangladesh. This finding is in agreement with the findings of Annalselvamalar et al. (2018) who reported that the prevalence of $E$. coli was $24.0 \%$ in milk and milk products in Chennai, India. In the current study, the prevalence $E$. coli was $26.0 \%$ in raw milk in Rajshahi Metropolitan area. This result is strongly supported by the findings of Zeinhom and Abdel-Latef (2014) who reported that the prevalence of $E$. coli was $26.7 \%$ in raw milk in Egypt. Similarly, Hassan et al. (2012) reported $20.9 \%$ prevalence of $E$. coli in raw milk in Iran. However, Asmahan and Warda (2011) reported 63.0\% prevalence of $E$. coli in raw milk in Sudan, and Hussain et al. (2014) reported $50.0 \%$ prevalence of E. coli in raw milk in Pakistan. The prevalence of $E$. coli in raw milk is indicative of poor hygienic measures during milking, irregular washing and sterilization of dairy equipments, utensils, milker hands and animal udders, infections of dairy cows which are used for milking purposes, and lack of public and individual hygiene (Sushma et al. 2012). The prevalence of E. coli was $34.0 \%$ in milk product (yogurt) in our study. Our finding is lower than the findings of Hussain et al. (2014) who reported that the prevalence of $E$. coli was $90.0 \%$ in Dahi in Pakistan and higher than the findings of Rahimi et al. (2011) who reported zero percent $(0.0 \%)$ prevalence of $E$. coli in yogurt in Iran. The prevalence results may vary due to difference in the origin of samples, technique used for collection and transportation of samples or environmental conditions. In the present study no $E$. coli was detected in pasteurized milk. However, Vahedi et al. (2013) reported that the prevalence of $E$. coli was $9.0 \%$ in pasteurized milk collected from super markets in Sari city in Iran. Survival of $E$. coli in pasteurized milk depends on the processing techniques of milk. Therefore, the absence of $E$. coli in pasteurized milk is consistent because the processing of these products could be performed at appropriate temperature and time. The occurrence of $E$. coli in milk and milk products probably due to the using of contaminated water in processing dairy product, infected people who produce dairy products, using contaminated equipments and finally lack of public and individual hygiene (Zhu et al. 2005). Isolated E. coli showed 100.0\%,60.0\%, 40.0\%, $40.0 \%, 33.3 \%, 33.3 \%, 20.0 \%$, and $10.0 \%$ resistance to penicillin, gentamycin, ampicillin, streptomycin, amoxycillin, sulfamethoxasole-trimethoprim, nalidixic acid, and ciprofloxacin, respectively. The isolates also showed $73.3 \%, 60.0 \%, 53.3 \%, 53.3 \%, 30.0 \%, 23.3 \%$, and $20 \%$ sensitive to ciprofloxacin, nalidixic acid, streptomycin, sulfamethoxasole-trimethoprim, amoxycillin, ampicillin, and gentamycin, respectively. Our results are in agreement with the findings of Rahimi et al. (2011) and Schroeder et al. (2002). Rahimi et al. (2011) reported that $44.4 \%, 44.4 \%, 33.3 \%, 11.1 \%$, and $11.1 \%$ E. coli isolated from milk and milk products were resistant to gentamycin, ampicillin, erythromycin, tetracycline, and nalidaxic acid, respectively. Schroeder et al. (2002) reported that 27.0\%, 26.0\%, 17.0\%, and 13.0\% isolates of $E$. coli from milk and milk products were resistant to tetracycline, sulphamethoxazole, cephalothin, and ampicillin, respectively. Similarly, Hossain et al. (2021) reported that $E$. coli isolated from chicken eggs were $71.42 \%, 71.42 \%$, $64.28 \%, 57.14 \%, 50.00 \%, 35.71 \%$, and $21.42 \%$ resistant to erythromycin, ampicillin, amoxicillin, tetracycline, ciprofloxacin, doxycycline, and chloramphenicol, respectively in Rajshahi district of Bangladesh. This study indicated that the antibiotic resistant bacteria which exist in the milk of infected animals can be transmitted to human by the ingestion of unpasteurized milk or milk products such as cheese, butter, yogurt and ice cream. However, the mechanism of spreading antibiotic resistant bacteria from food animals to human remains controversial (Adeleke et al. 2000). 


\section{Conclusion}

In the present study, the overall prevalence E. coli was $20.0 \%$ in milk and milk product (yogurt) in Rajshahi Metropolitan area of Bangladesh. Isolated E. coli showed 100.0\%, 60.0\%, 40.0\%, 40.0\%, 33.3\%, 33.3\%, $20.0 \%$, and $10.0 \%$ resistance to penicillin, gentamycin, ampicillin, streptomycin, amoxycillin, sulfamethoxasole-trimethoprim, nalidixic acid, and ciprofloxacin, respectively. In the context of this study, the prevalence of $E$. coli in raw milk and milk product, and their antibiotic resistance is obviously significant. It could be concluded that the antibiotic resistant $E$. coli from raw milk and milk product may pose a public health hazard to consumers. Thus, the use of antibiotics in the dairy industry should be limited to reduce the development of antibiotic resistant $E$. coli strain.

\section{Acknowledgement}

This research work was financially supported by University Grand Commission (UGC) of Bangladesh is gratefully acknowledged.

\section{References}

Adeleke OE, Adeniyi BA and Akinrinmisi AA (2000). Microbiological quality of local soymilk: a public health appraisal. African Journal of Biochemical Research, 3: 89-92.

Annalselvamalar P, Sekar M, Porteen K, Narayan R, Elango A, Kummar MA, Sowmiya M and Devi T (2018). Screening of $E$. coli for its antimicrobial susceptibility pattern in milk and dairy products in Chennai, India. International Journal of Chemical Studies, 6: 35-37.

Asmahan AA and Warda SA (2011). Incidence of Escherica coli in raw cow's milk in Khartoum state. British Journal of Dairy Sciences, 2(1): 23-26.

Bauer AW, Kirby WMM, Shrris JC and Truck M (1966). Antibiotic susceptibility testing by standardized single disk method. American Journal of Clinical Pathology, 45: 493-496.

Cheesbrough M (1985). Medical Laboratory Manual for Tropical Countries. 1'st Edition. In: Microbiolgy, Doddington, UK.

Clinical and Laboratory Standards Institute (CLSI) (2017). Performance Standards for Antimicrobial Susceptibility Testing. $26^{\text {th }}$ Edition. CLSI supplement M100S. Wayne, Pennsylvania, USA.

Cowan S. T (1985). Cowan and Steel's Manual for Identification of Medial Bacteria. $2^{\text {nd }}$ Edition. Cambridge University Press, Cambridge, London.

Eckburg PB, Bik EM, Bernsein CN, Purdomj E and Dethlefsenj ET (2009). Diversity of the human intestinal microbial flora. Science, 308 (5728): 1635- 1638.

Hassan M, Farzan R, Rahimi E, Dehkordi FS and Souod N (2012). Molecular characterization of Shiga toxin-producing Escherichia coli isolated from ruminant and donkey raw milk samples and traditional dairy products in Iran. The Scientific World Journal, 12: 13-26.

Hossain MS, Rahman W, Ali MS, Sultana T and Hossain KMM (2021). Identification and antibiogram assay of Escherichia coli isolated from chicken eggs. Journal of Bio-Science, 29(1): 123-133.

Hussain A, Ali S, Shakir HA, Qazi JI, Ali N and Ullah N (2014). Prevalence of Eschericha coli in milk and different milk products sold under market conditions at Lahore. Scientific Journal of Animal Science, 3(1): 22-26. 
Jorgensen JH and Turnidge JD (2015). Susceptibility test methods: dilution and disk diffusion methods, Manual of Clinical Microbiology. $11^{\text {th }}$ Edition. American Society for Microbiology, Washington, DC.

Kaddu-Mulindw DH, Aisu T, Gleier K, Zimmermann S and Beutinl (2001). Occurrence of Shiga toxin-producing Escherichia coli in fecal samples from children with diarrhea and from healthy zebu cattle in Uganda. International Journal of Food Microbiology, 66: 95-101.

Levine MM (1984). Escherichia coli that cause diarrhea: Enterotoxigenic, Enteroinvasive, Enterohaemorrhagic and Enteradherent. Journal of Infectious Diseases, 155: 119-121.

Marshall B, Petrowski D and Levy SB (1990). Inter and intra species spread of Escherichia coli in a farm environment in the absence of antibiotic use. Proceedings of the National Academy Science, 87: 6609-6613.

Merchant IA and Packer RA (1967). Veterinary Bacteriology and Virology. $7^{\text {th }}$ Edition. The lowa University Press, USA.

Qadri F, Svennerholm AM, Faruque AS and Sack RB (2005). Enterotoxigenic Escherichia coli in developing countries. Epidemiology Microbiology Reviews, 18: 465-483.

Rahimi E, Chaleshtori SS and Parsaei P (2011). Prevalence and antimicrobial resistance of Escherichia coli 0-157 isolated from traditional cheese, ice cream and yoghurt in Iran. African Journal of Microbiology Research, 5 (22): 3706-3710.

Rani B and Maheshwari R (2012). Biochemical and microbiological aspects of milk: A review. Bulletin of Environment, Pharmacology and Life Sciences, 1: 57-63.

Saylers AA and Whitt DD (2002). Diarrhoeagenic Escherichia coli strains. In: Bacterial Pathogenesis, A Molecular Approach. $2^{\text {nd }}$ Editon. ASM Press, American Society for Microbiology, USA.

Schroeder CM, Zhao C and Roy DC (2002). Antimicrobial resistance of Escherichia coli 0-157 isolated from humans, cattle, swine, and food. Applied and Environmental Microbiology, 68(2): 576-581.

Smith HW and Haibs W (1967). Observation by the ligated intestinal segments and oral inoculation methods of Escherichia coli in calves, lambs, pigs, and rabbits. Infection and Immunity, 93: 499-529.

Smith K, Peter K, Daniela H and Melchior S (2007). Food borne pathogenic microorganisms and natural toxins. Food Safety and Applied Nutrition, 10: 119-150.

Sushma K, Mahalakshmi MR and Sridevi M (2012). Morphological and biochemical characteristics and antibiotic resistance pattern of Staphylococcus aureus isolated from milk samples. International Journal of Nutrition, Pharmacology and Neurological Diseases, 2: 70-73.

Vahedi M, Nasrolahei M, Sharif M and Mirabi AM (2013). Bacteriological study of raw and unexpired pasteurized cow's milk collected at the dairy farms and super markets in Sari city in Iran. Journal of Preventive Medicine and Hygiene, 54: 120-123.

Zeinhom MMA and Abdel-Latef GK (2014). Public health risk of some milk borne pathogens. Beni-Suef University Journal of Basic and Applied Sciences, 3: 209-215.

Zhu P, Shelton DR, Karns JS, Sundaram A, Li S, Amstutz P and Tang C (2005). Detection of water borne E. coli O 157 using the integrating waveguide biosensor. Biosensors and Bioelectronics, 21(4): 678-683. 